\title{
The Kinetics and Dry-Sliding Wear Properties of Boronized Gray Cast Iron
}

\author{
Dong $\mathrm{Mu}^{1}$ and Bao-luo Shen ${ }^{2}$ \\ ${ }^{1}$ Department of Mechanical Engineering, Chengdu Technological University, Chengdu 611730, China \\ ${ }^{2}$ College of Materials Science and Engineering, Sichuan University, Chengdu 610064, China \\ Correspondence should be addressed to Dong Mu; xhmd@163.com
}

Received 30 May 2013; Accepted 15 July 2013

Academic Editor: Yong Ding

Copyright (c) 2013 D. Mu and B.-l. Shen. This is an open access article distributed under the Creative Commons Attribution License, which permits unrestricted use, distribution, and reproduction in any medium, provided the original work is properly cited.

\begin{abstract}
Some properties of boride formed on gray cast iron (GCI) have been investigated. GCI was boronized by powder-pack method using Commercial LSB-II powders at 1123, 1173, and $1223 \mathrm{~K}$ for 2, 4, 6, and $8 \mathrm{~h}$, respectively. Scanning electron microscopy showed that boride formed on the surface of boronized GCI had tooth-shaped morphology. The hardness of boride formed on surfaces of GCI ranged from 1619 to $1343 \mathrm{HV}_{0.025}$, and quenched and tempered GCI ranged from 400 to $610 \mathrm{HV}_{0.025}$. The boride formed in the coating layer confirmed by X-ray diffraction analysis was $\mathrm{Fe}_{2} \mathrm{~B}$ single phase. Depending on boronizing time and temperature, the thickness of coating layers on boronized GCI ranged from 26 to $105 \mu \mathrm{m}$. The activation energy was $209 \mathrm{~kJ} / \mathrm{mol}$ for boronized GCI. Moreover, the possibility of predicting the iso-thickness of boride layers variation was studied. Dry-sliding wear tests showed that the wear resistance of boronized sample was greater than that of quenched and tempered sample.
\end{abstract}

\section{Introduction}

Gray cast iron (GCI), which contains $2.5-5 \% \mathrm{C}$ and $0.8-3 \%$ $\mathrm{Si}$, is the most used material in machinery manufacturing because it possesses many technical advantages [1-4]. Nowadays, GCI is still used in 65\% of casting parts because of its performance advantage and low cost. Lamellar graphite on GCI shows superior abrasion resistance, hardness, perfect machinability, limited lubricated-friction resistance, and vibration-absorption properties. These materials are comparable with steel in terms of pressing resistance, dimensional balance, and retention of their plastic shape under tension [57].

Boronizing is a thermochemical diffusion surface treatment in which boron atoms are diffused into the surface of work piece to form hard borides with the base material $[8,9]$, and it is a prominent where the control of friction and wear is of primary concern [10]. It is successfully applied to all ferrous materials, nickel alloys, titanium alloys, and sintered carbides $[11,12]$. In recent years, several investigations have been carried out on the boronized cast irons [13-16]. However, few researchers have worked on the growth kinetics and the dry-sliding wear behavior of boronized GCI with singlephase $\left(\mathrm{Fe}_{2} \mathrm{~B}\right)$. To control the boronizing processes, knowledge of kinetic parameters is essential. It is very important to establish the variables that affect the boronizing kinetics process to control automated procedures and obtain desirable properties. For practical applications, the formation of a single-phase $\left(\mathrm{Fe}_{2} \mathrm{~B}\right)$ is more desirable than a dual layer comprising $\mathrm{FeB}$ and $\mathrm{Fe}_{2} \mathrm{~B}$. This is because, although the boron-rich $\mathrm{FeB}$ phase is harder, it is more brittle than the iron subboride, $\mathrm{Fe}_{2} \mathrm{~B}$ phase. Furthermore, crack formation is often observed at the $\mathrm{FeB} / \mathrm{Fe}_{2} \mathrm{~B}$ interface of a dual-phase layer, as $\mathrm{FeB}$ and $\mathrm{Fe}_{2} \mathrm{~B}$ phases exhibit substantially different coefficients of thermal expansion. These cracks often lead to flaking when a mechanical load is applied [17]. Therefore, the purpose of this paper is to investigate the kinetics boronized GCI. Furthermore, the wear properties of the quenched and tempered GCI and the boronized GCI are investigated using a ring-on-block wear tester under dry-sliding conditions.

\section{Methods and Procedures}

2.1. Substrate Materials. The substrate material used in this study was the GCI with its chemical composition given in Table 1. The test samples had a dimension of $10 \mathrm{~mm} \times 10 \mathrm{~mm} \times 10 \mathrm{~mm}$. Before treating, all the samples 


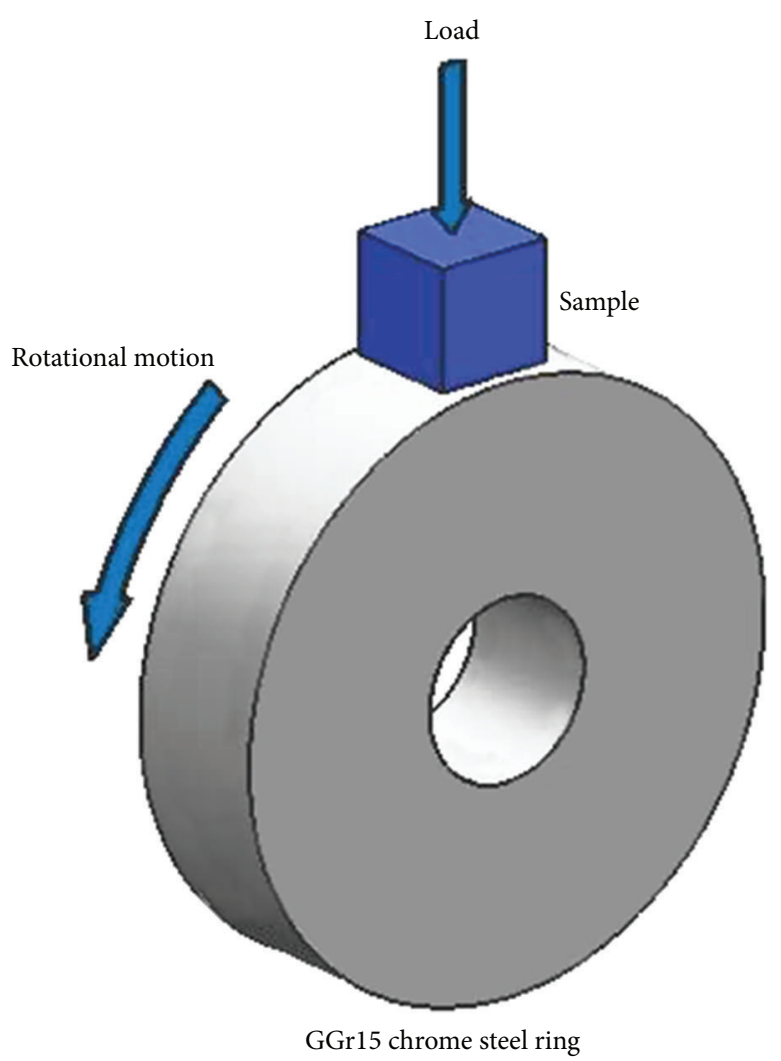

Figure 1: Schematic illustration of the wear test device.

TABLE 1: Chemical composition of the GCI (wt.\%).

\begin{tabular}{lccccccccc}
\hline $\mathrm{C}$ & $\mathrm{Si}$ & $\mathrm{Mn}$ & $\mathrm{Cr}$ & $\mathrm{Ni}$ & $\mathrm{Mo}$ & $\mathrm{V}$ & $\mathrm{Ti}$ & $\mathrm{P}$ & $\mathrm{S}$ \\
\hline 3.57 & 2.06 & 0.56 & 0.78 & 0.25 & 0.32 & 0.03 & 0.08 & 0.07 & 0.03 \\
\hline
\end{tabular}

were ground using 600 grid emery paper to get surface finished and degreased ultrasonically in acetone and dried.

2.2. Treatments. Two different heat treatment procedures including (1) quenching and tempering and (2) boronizing were followed. For quenching and tempering, GCI samples after holding at the electrical resistance furnace for $10 \mathrm{~min}$ were quickly oil-quenched from the temperature $1173 \mathrm{~K}$ and then tempered at $473 \mathrm{~K}$ for $2 \mathrm{~h}$, followed by cooling in room temperature. Boronizing was performed in a solid medium by using Commercial LSB-II powders that had a nominal chemical composition of $88 \% \mathrm{SiC}, 8 \% \mathrm{~B}_{4} \mathrm{C}$, and $4 \% \mathrm{KBF}_{4}$. All samples to be boronized were packed in the powders mix and sealed in a stainless steel container. Boronizing was performed in an electrical resistance furnace under atmospheric pressure at 1123,1173 , and $1223 \mathrm{~K}$ for $2,4,6$, and $8 \mathrm{~h}$, respectively, followed by furnace cooling.

2.3. Characterization. The microstructure of the polished and etched cross-section of the samples was observed by scanning electron microscopy (SEM, HITACHI S-3400N) equipped with energy dispersive spectroscopy. The Philip XRay Diffractometer was employed to examine the phase composition of the coating layer, with the radiation $\mathrm{Cu}-\mathrm{K}_{\alpha}$, the tube voltage $40 \mathrm{kV}$, and the tube current $25 \mathrm{~mA}$. The hardness measurements of the layers formed surface were performed using the Vickers microhardness tester (SHIMADZU/HMV2) with the loads of $25 \mathrm{~g}$.

2.4. Kinetic. The growth kinetics of the layer is controlled by the boron diffusion into the $\mathrm{Fe}_{2} \mathrm{~B}$, and the growth of boride layer occurs as a consequence of the boron diffusion perpendicular to the ample surface. Fick's laws establish the concentrations of boron in the $\mathrm{FeB}$ and $\mathrm{Fe}_{2} \mathrm{~B}$. The boride layer growing obeys the parabolic law [18]:

$$
d^{2}=K t
$$

where $d$ is the boride layer thickness $(\mu \mathrm{m}), t$ is treatment time ( $\mathrm{min}$ ), and $K$ is boron growth rate constant depending on boronizing temperature and is calculated from the slopes of the $d^{2}$ versus treatments time graphs. The relationship between the growth rate constant, $K$, activation energy, $Q$, and temperature, $T$, can be expressed as an Arrhenius equation [19]:

$$
K=K_{0} \exp \left(-Q R^{-1} T^{-1}\right),
$$

where $K_{0}$ is a preexponential constant (independent temperature), $Q$ is activation energy $\left(\mathrm{Jmol}^{-1}\right), T$ is the absolute temperature in Kelvin, and $R$ is the gas constant (8.314 $\mathrm{Jmol}^{-1} \mathrm{~K}^{-1}$ ). Taking the natural logarithm of (2), the following can be derived:

$$
\ln K=\ln K_{0}+\left(-Q R^{-1}\right)\left(T^{-1}\right) .
$$




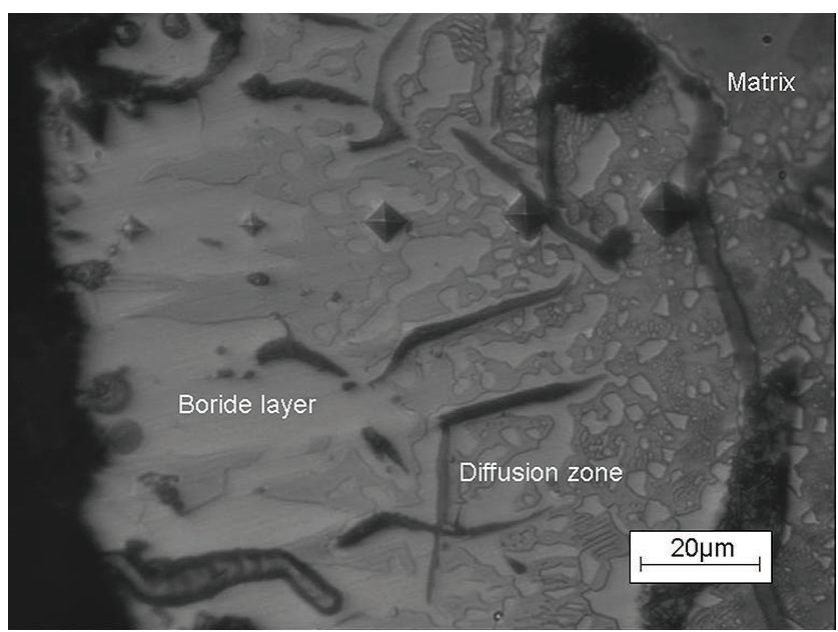

(a)

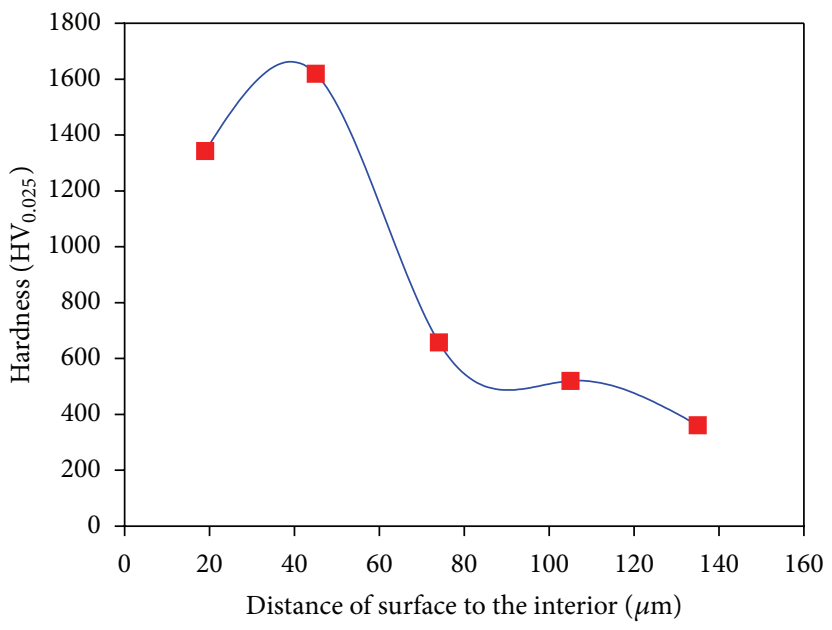

(b)

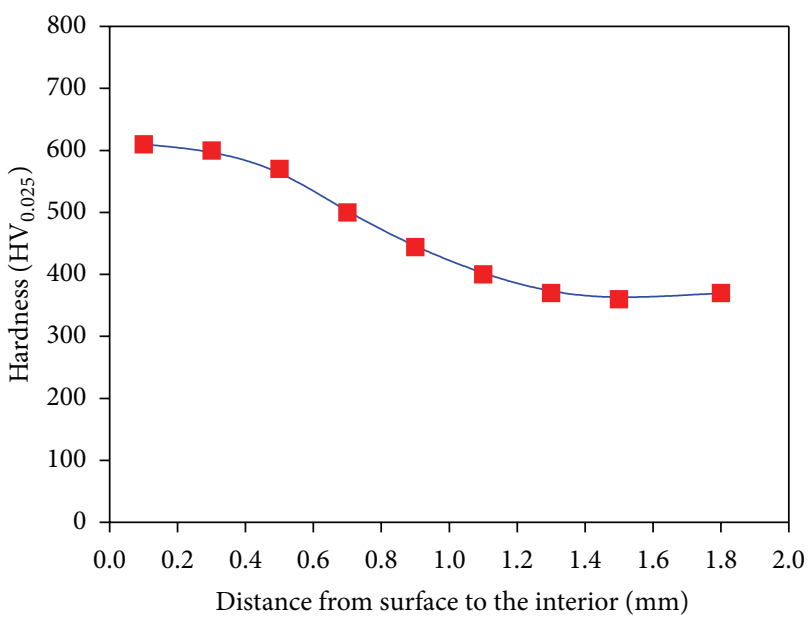

(c)

FIgURE 2: (a) Optical micrographs of the boronized at GCI $1223 \mathrm{~K}$ for $6 \mathrm{~h}$, showing the hardness indentation variation with distance from surface to interior; (b) hardness values of the boronized GCI at $1223 \mathrm{~K}$ for $6 \mathrm{~h}$; (c) hardness values of the quenched and tempered GCI.

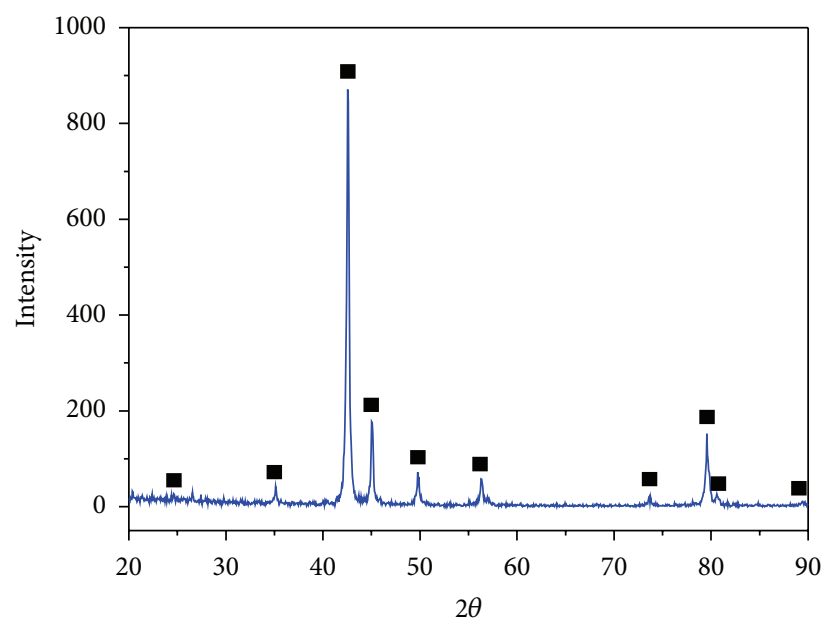

- $\mathrm{Fe}_{2} \mathrm{~B}$

FiguRE 3: X-ray diffraction patterns of GCI boronized at $1223 \mathrm{~K}$ for $8 \mathrm{~h}$. 


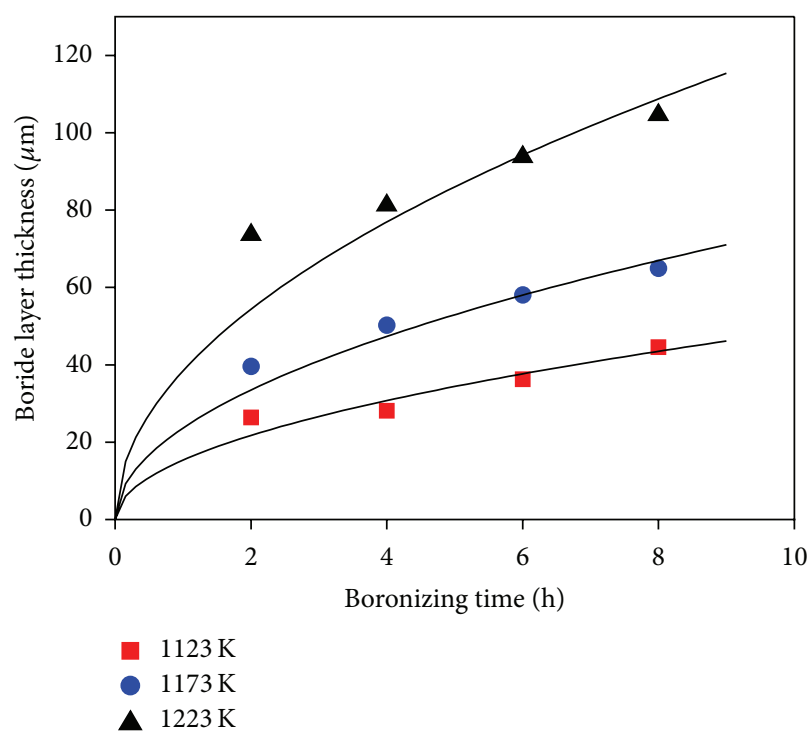

(a)

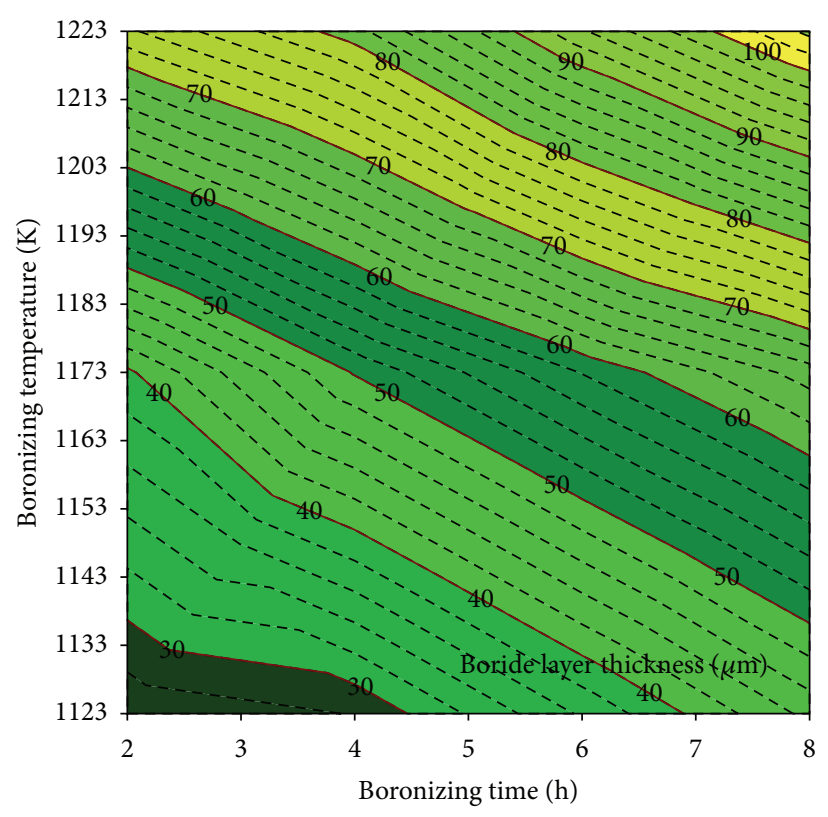

(b)

FIgURE 4: (a) Boride layer thickness formed on GCI as a function time and temperature; (b) the contour diagram of boride layer thickness of boronized GCI.

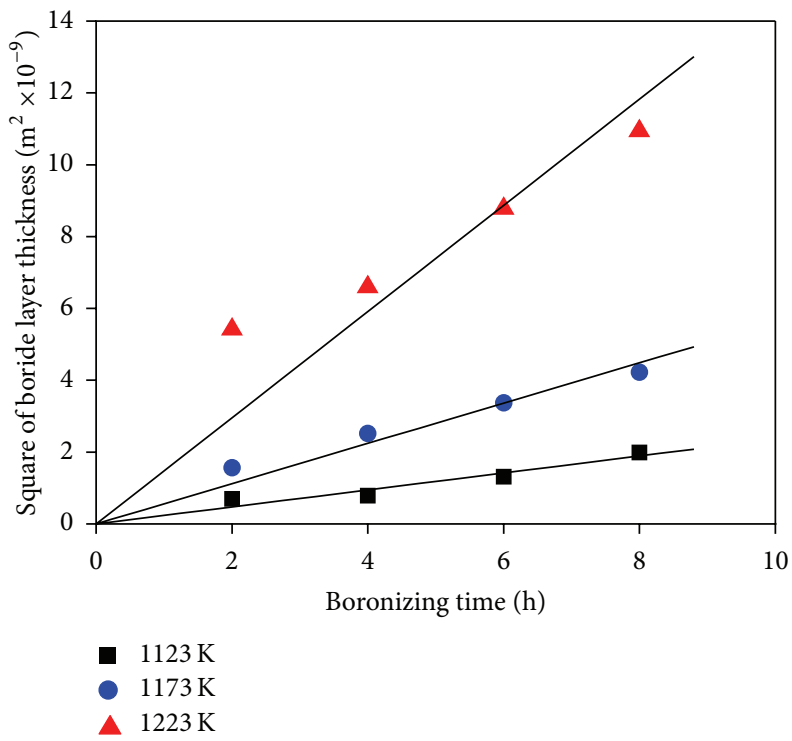

FIgURE 5: Square of boride layer thickness of boronized GCI as a function process time.

Consequently, the activation energy for the boron diffusion in the boride layer is determined by the slope obtained by the plot $\ln K$ versus $1 / T$ using (3).

2.5. Wear Tests. Wear tests were carried out on a Type M200 ring-on-block wear tester. A schematic view of the tester is shown in Figure 1. The tests were performed at a constant speed of $200 \mathrm{rpm}$ (equating to a linear sliding velocity of $52.3 \mathrm{~cm} / \mathrm{s}$ ) for duration of $3600 \mathrm{~s}$. A normal operating load of $30 \mathrm{~N}$ was used. For the counter body, $50 \mathrm{~mm}$ diameter GGr15 chrome steel rings (HRC52) were selected. The wear losses were measured by Type TG328A analytic balance with sensitivity of $0.1 \mathrm{mg}$. The wear rates of samples were calculated using the equation of $K=W / S$, where $W$ is the wear weight in $\mathrm{mg}$ and $S$ is the total sliding distance in $\mathrm{km}$. The worn surface morphologies of the samples were also observed by Type JSM5910-LV scanning electron microscopy (SEM).

\section{Results and Discussion}

3.1. Microstructure and Hardness. Figure 2 shows optical images of the etched cross-section of the GCI boronized at $1223 \mathrm{~K}$ for $6 \mathrm{~h}$. As seen in Figure 2(a), it is observed that 


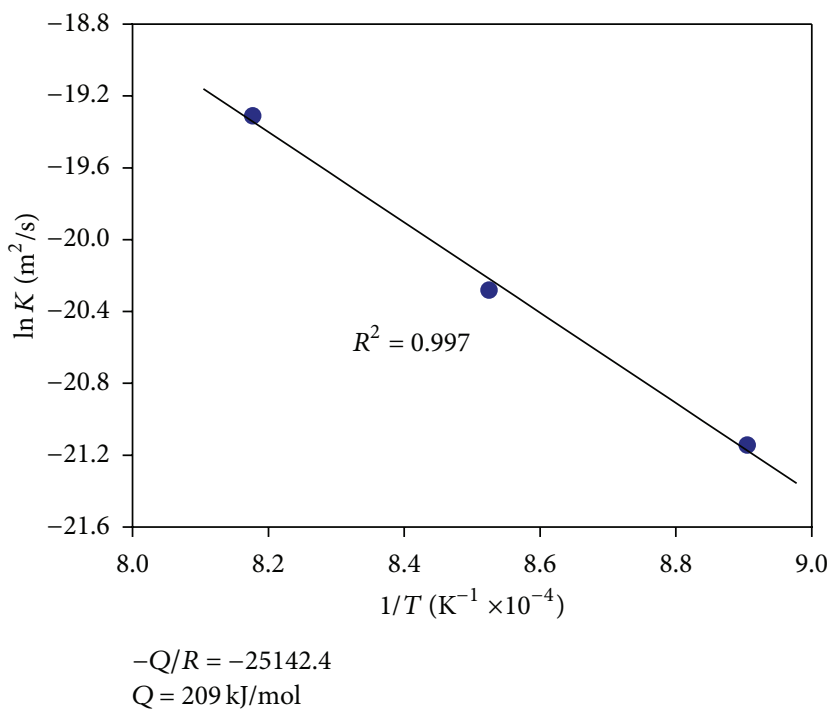

FIGURE 6: $\ln K$ versus 1/T for boronized GCI.

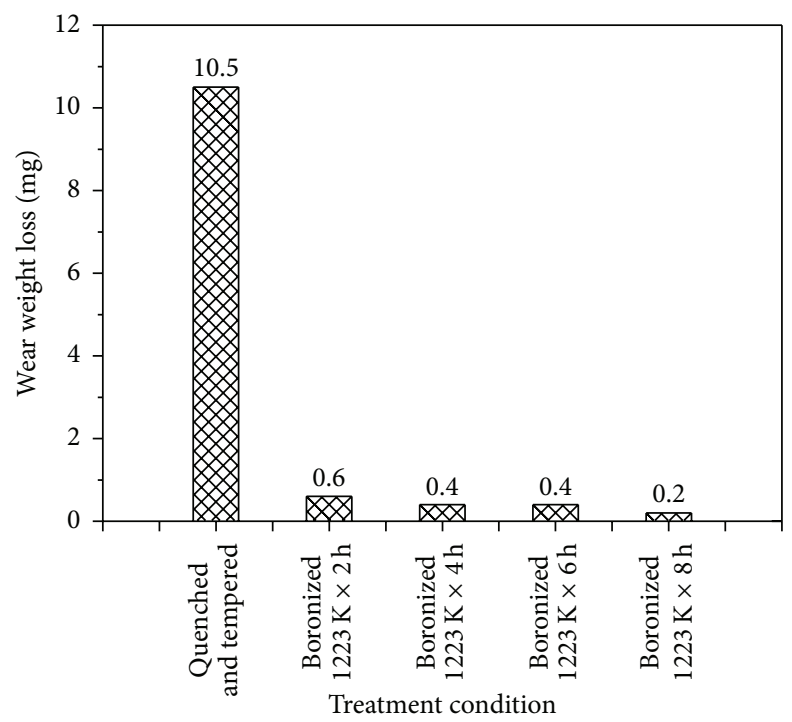

Figure 7: The figure shows the wear weight loss of quenched and tempered GCI and boronized GCI at $1223 \mathrm{~K}$ through the wear tests.

boride formed on GCI has tooth-shaped morphology. Moreover, three distinct regions are identified on cross-sections of boronized GCI surface. These are (1) a surface layer, consisting of boride phase; (2) a diffusion zone, being rich in boron; and (3) the matrix. The hardness values of boronized GCI are given in Figure 2(b). The hardness of boronized GCI ranged between 1619 and $1343 \mathrm{HV}_{0.025}$ and that of unboronized GCI is about $350 \mathrm{HV}_{0.025}$ (see Figure 2(c)). Hardness measurements show that the hardness of boride layers is much higher than that of matrix. The differences in hardness values of the boride layers are a consequence of the presence of structural defects (i.e., porosity, cracks, etc.). The hardness gradient was obtained for quenched and tempered GCI varying from about 400 to $610 \mathrm{HV}_{0.025}$ at a distance of $1.1 \mathrm{~mm}$, which is the hardened layer thickness.

3.2. XRD Analysis. In Figure 3, the XRD patterns of the boronized GCI at $1223 \mathrm{~K}$ during $8 \mathrm{~h}$ are shown. In all patterns, the peaks are those of the $\mathrm{Fe}_{2} \mathrm{~B}$ phase only. It is known that media with lower intermediate boron potential (as compared to more powerful ones) allow single $\mathrm{Fe}_{2} \mathrm{~B}$ layers to form [20]. In commercial LSB-II powders, the use of the silicon carbide ( $\mathrm{SiC}$ ) as a reducing agent lies in better control for formation of a single-phase layer $\left(\mathrm{Fe}_{2} \mathrm{~B}\right)$. Consequently, the $\mathrm{FeB}$ phase did not form.

3.3. Kinetic Studies. Depending on the boronizing temperature and time, the thickness of boride layers on boronized GCI ranges from 26 to $105 \mu \mathrm{m}$. Figure 4(a) shows the boride layer thickness of GCI as a function of time. As the boronizing time and temperature increase, the thickness of the boride layer increases. In addition, contour diagrams are utilized from the data of Figure 4(a) facilities by means of Sigma Plot 10.0 software (see Figure 4(b)). The contour diagram derived from Figure 4(a) may facilitate the choosing of process parameters in industrial applications. In order to calculate 


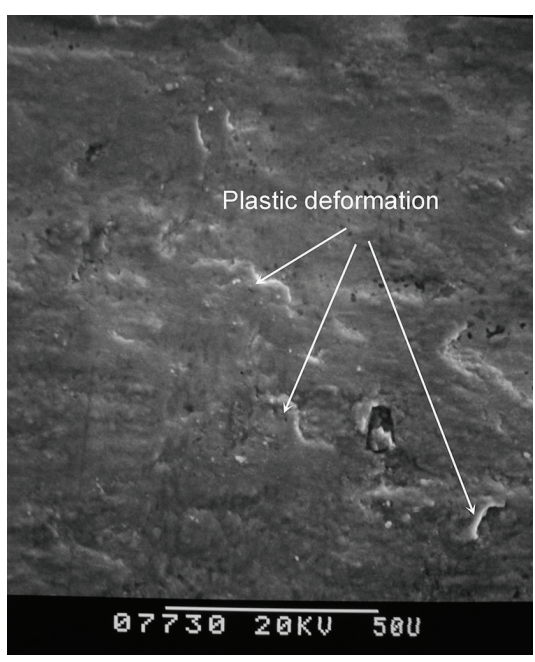

(a)

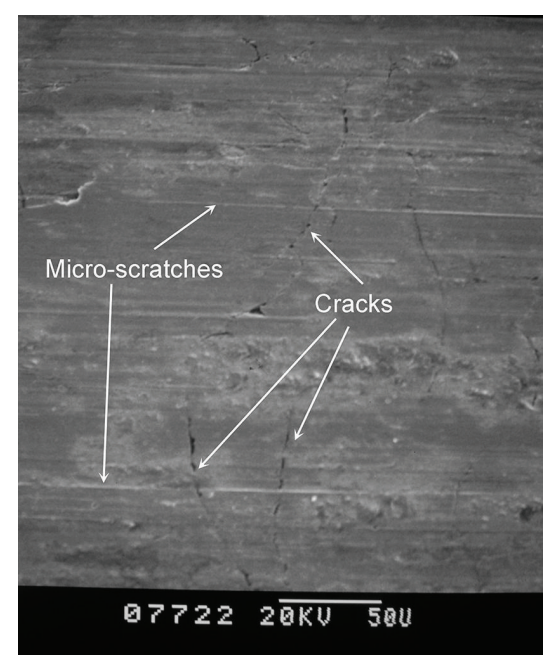

(b)

FIGURE 8: SEM micrographs of the worn surfaces of (a) quenched and tempered GCI; (b) boronized GCI at $1223 \mathrm{~K}$ for $8 \mathrm{~h}$.

the activation energy of diffusion controlled process, square of layer thickness is described as a function of rate constant and process time, that is, $d^{2}=K t$, where $K$ is rate constant and $t$ is process time. If the kinetics of layer progress for the periods between 2 and $8 \mathrm{~h}$ is considered, it can be recognized that the layer thickness changes linearly with time as seen in Figure 5. The plot of rate constant versus reciprocal boronizing temperature reveals a linear relationship (Figure 6), and activation energy of $209 \mathrm{~kJ} / \mathrm{mol}$ for GCI is determined from the slope of the straight lines.

3.4. Wear Behavior. The wear weight losses of quenched and tempered GCI and boronized GCI at $1223 \mathrm{~K}$ are presented in Figure 7 . Only the boronized samples were considered, the least wear against the GGr15 chrome steel rings was seen in that boronized for $8 \mathrm{~h}$, and the highest wear was seen in that treated for $2 \mathrm{~h}$. Furthermore, it was also observed that the increasing thickness of borided layer increases the wear resistance. As a result of the comparison made for wear of all treatment conditions, it is clearly observed that the quenched and tempered samples were worn more than the boronized samples involved. The hardness of boride layer plays an important role in improvement of the wear resistance.

The SEM observations of worn surfaces of the quenched and tempered GCI and boronized GCI are shown in Figure 8. For the quenched and tempered GCI sample, due to its low surface hardness, it can be observed that the worn surface is deformed under the dry-sliding wear condition (see Figure 8(a)). This is due to the fact that during the sliding course, a plastic deformation mechanism which is typical of the adhesive wear is found superficially resulting from superficial material detachment. Therefore, wear weight loss of quenched and tempered GCI is much higher than that of the boronized samples. SEM micrographs of the worn surface of the boronized samples are shown in Figure 8(b). The microscratches with slight plastic deformation are observed on the worn surface of the treated samples at $1223 \mathrm{~K}$ for $8 \mathrm{~h}$, indicating that a mild adhesive wear and abrasive wear occurred. Therefore, the improved dry-sliding wear resistance of the treated sample is obtained. Unfortunately, under such test condition that the samples are performed on the ring slider under the applied normal load of $30 \mathrm{~N}$ in dry-sliding wear test, very high contact stress would occur [21], and thus boride layer is cracked by loads due to its higher hardness.

\section{Conclusion}

The conclusions derived from the present study can be summarized as follows.

(1) The boride formed on the gray cast iron (GCI) has tooth- shaped morphology. It was observed that boride layers have three distinct regions: (1) boride layer; (2) diffusion zone; and (3) matrix.

(2) The hardness values of boride formed on the surface of GCI ranged from 1619 to $1343 \mathrm{HV}_{0.025}$, while the unboronized GCI substrate was about $350 \mathrm{HV}_{0.025}$. The hardness values of quenched and tempered GCI varied from about 400 to $610 \mathrm{HV}_{0.025}$.

(3) X-ray diffraction study revealed that GCI boronized by using Commercial LSB-II powders causes a singlephase $\left(\mathrm{Fe}_{2} \mathrm{~B}\right)$ boride layer formed on the surface of GCI.

(4) It was observed that there is nearly a parabolic relationship between thickness of the layer and boronizing time. Boride layers ranged in thickness from 26 to $105 \mu \mathrm{m}$ as a function of boronizing time and temperature. Longer times and higher temperatures result in a thicker layer.

(5) The activation energy for the boron diffusion in the coating layer is determined to be $209 \mathrm{~kJ} / \mathrm{mol}$. A contour diagram was established for predicting the depth of coating layer as a function of process time and temperature for industrial applications. 
(6) Boronizing was a more effective treatment to improve the wear properties of GCI compared with quenched GCI under the dry-sliding wear condition.

\section{Acknowledgment}

This study was supported by Research Fund for the Doctoral Program of Higher Education of China.

\section{References}

[1] H. Berns, "Comparison of wear resistant MMC and white cast iron,” Wear, vol. 254, no. 1-2, pp. 47-54, 2003.

[2] C. Kowandy, C. Richard, Y.-M. Chen, and J.-J. Tessier, "Correlation between the tribological behaviour and wear particle morphology-case of grey cast iron 250 versus Graphite and PTFE," Wear, vol. 262, no. 7-8, pp. 996-1006, 2007.

[3] E. Albertin and A. Sinatora, "Effect of carbide fraction and matrix microstructure on the wear of cast iron balls tested in a laboratory ball mill," Wear, vol. 250-251, no. 1, pp. 492-501, 2001.

[4] J. Asensio, J. A. Pero-Sanz, and J. I. Verdeja, "Microstructure selection criteria for cast irons with more than $10 \mathrm{wt} . \%$ chromium for wear applications," Materials Characterization, vol. 49, no. 2, pp. 83-93, 2002.

[5] B. K. Prasad, O. P. Modi, and H. K. Khaira, "High-stress abrasive wear behaviour of a zinc-based alloy and its composite compared with a cast iron under varying track radius and load conditions," Materials Science and Engineering A, vol. 381, no. 1-2, pp. 343-354, 2004.

[6] T. Murakami, T. Inoue, H. Shimura, M. Nakano, and S. Sasaki, "Damping and tribological properties of Fe-Si-C cast iron prepared using various heat treatments," Materials Science and Engineering A, vol. 432, no. 1-2, pp. 113-119, 2006.

[7] A. K. Tieu and Y. J. Liu, "Friction variation in the cold-rolling process," Tribology International, vol. 37, no. 2, pp. 177-183, 2004.

[8] A. K. Sinha, "Boriding (Boronizing) of steels," ASM International, Heat Treating, vol. 4, pp. 437-447, 1991.

[9] R. H. Biddulph, "Boronizing for erosion resistance," Thin Solid Films, vol. 45, no. 2, pp. 341-347, 1977.

[10] A. Erdemir and C. Bindal, "Formation and self-lubricating mechanisms of boric acid on borided steel surfaces," Surface and Coatings Technology, vol. 76-77, no. 1, pp. 443-449, 1995.

[11] O. Torun, R. Gürler, B. Baksan, and I. Celikyürek, "Diffusion bonding of iron aluminide $\mathrm{Fe}_{72} \mathrm{Al}_{28}$ using a pure iron interlayer," Intermetallics, vol. 13, no. 8, pp. 801-804, 2005.

[12] L. Pan and D. E. Luzzi, "A study on diffusion couples of Ti and polysynthetically twinned (PST) Ti-Al: I. Microstructure characterization," Intermetallics, vol. 14, no. 1, pp. 61-67, 2006.

[13] U. Sen, S. Sen, S. Koksal, and F. Yilmaz, "Fracture toughness of borides formed on boronized ductile iron," Materials and Design, vol. 26, no. 2, pp. 175-179, 2005.

[14] R. Ipek, B. Selçuk, M. B. Karamiş, V. Kuzucu, and A. Yücel, "An evaluation of the possibilities of using borided GG25 cast iron instead of chilled GG25 cast iron (surface properties)," Journal of Materials Processing Technology, vol. 105, no. 1-2, pp. 73-79, 2000.

[15] U. Sen, S. Sen, and F. Yilmaz, "Effect of copper on boride layer of boronized ductile cast irons," Vacuum, vol. 72, no. 2, pp. 199204, 2003.
[16] C. Meric, S. Sahin, B. Backir, and N. S. Koksal, "Investigation of the boronizing effect on the abrasive wear behavior in cast irons," Materials and Design, vol. 27, no. 9, pp. 751-757, 2006.

[17] C. Martini, G. Palombarini, G. Poli, and D. Prandstraller, "Sliding and abrasive wear behaviour of boride coatings," Wear, vol. 256, no. 6, pp. 608-613, 2004.

[18] W. Jost, Diffusion in Solids, Liquids, Gases, Academic Press, New York, NY, USA, 3rd edition, 1960.

[19] F.-S. Chen and K.-L. Wang, "The kinetics and mechanism of multi-component diffusion on AISI 1045 steel," Surface and Coatings Technology, vol. 115, no. 2-3, pp. 239-248, 1999.

[20] I. Campos, O. Bautista, G. Ramírez, M. Islas, J. De La Parra, and L. Zúñiga, "Effect of boron paste thickness on the growth kinetics of $\mathrm{Fe}_{2} \mathrm{~B}$ boride layers during the boriding process," Applied Surface Science, vol. 243, no. 1-4, pp. 429-436, 2005.

[21] C. X. Li and T. Bell, "Sliding wear properties of active screen plasma nitrided 316 austenitic stainless steel," Wear, vol. 256, no. 11-12, pp. 1144-1152, 2004. 

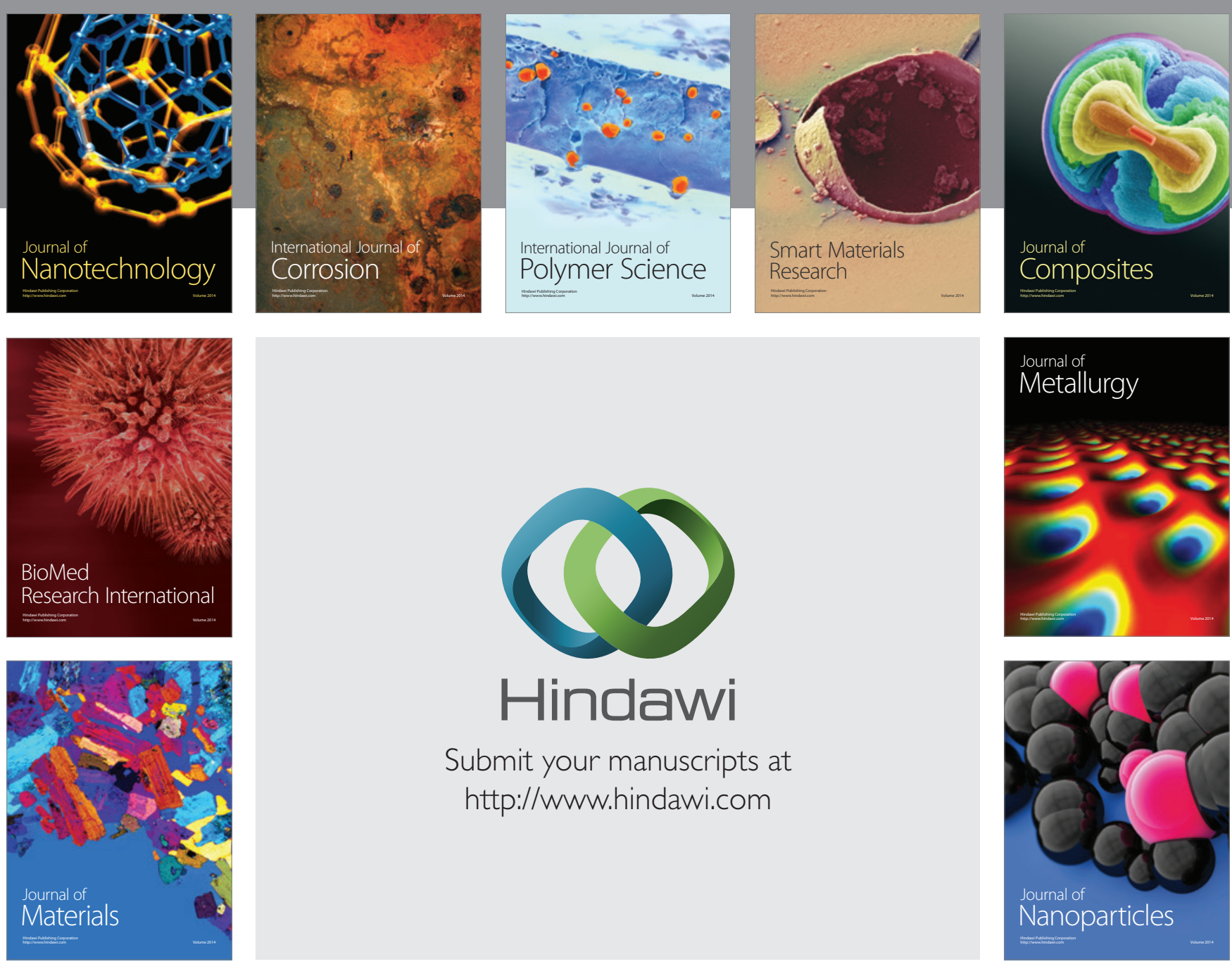

Submit your manuscripts at http://www.hindawi.com
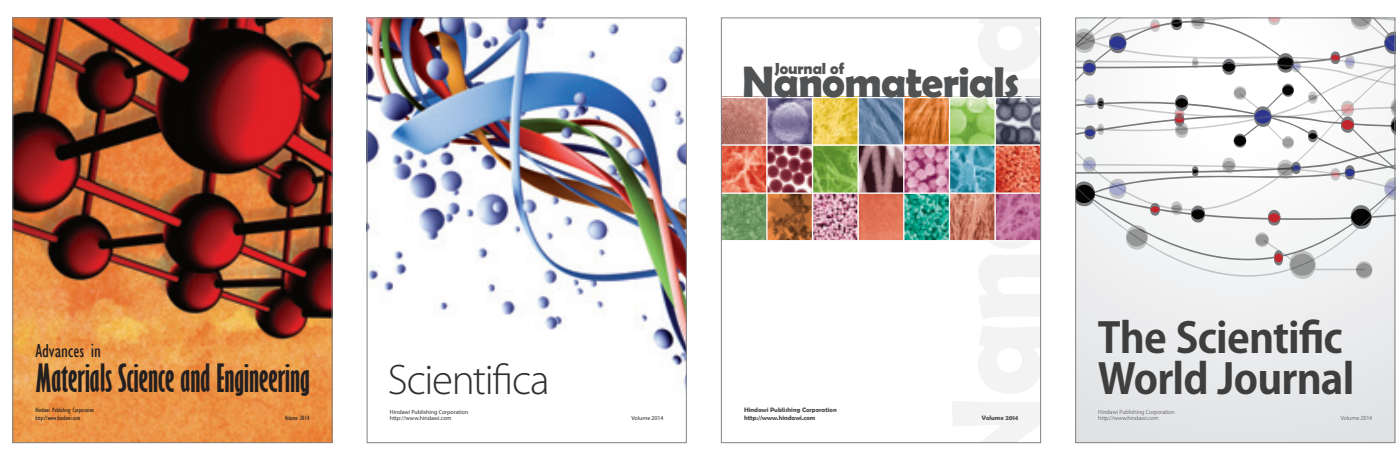

\section{The Scientific World Journal}
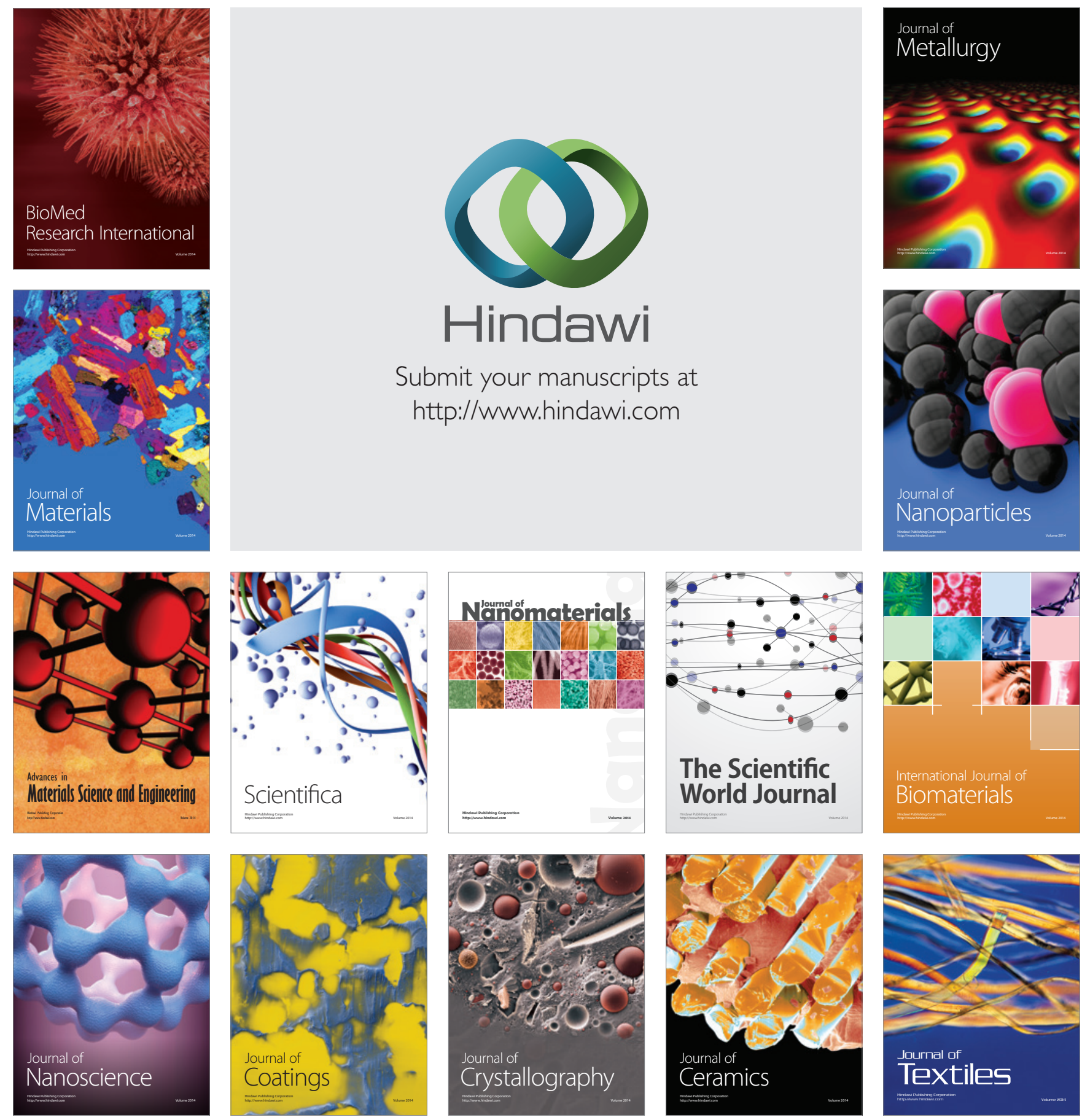